\title{
Scientific collaboration of Library \& Information Science research in China (2012-2013)
}

\author{
Munazza Jabeen ${ }^{1,2}$, Muhammad Imran ${ }^{3}$ Kamal Badar, Muhammad Rafiq ${ }^{5}$, \\ Misbah Jabeen ${ }^{6}$ and Liu Yun ${ }^{2}$ \\ ${ }^{1}$ Department of Library and Information Science, \\ University of Balochistan, Quetta, PAKISTAN \\ ${ }^{2}$ School of Management and Economics, Beijing Institute of technology, \\ Beijing 100081, CHINA \\ ${ }^{3}$ Institute of Geo-Information Science \& Earth Observation (IGEO), \\ PMAS Arid Agriculture University, Rawalpindi, PAKISTAN \\ ${ }^{4}$ Institute of Management Science, University of Balochistan, \\ Quetta, PAKISTAN \\ ${ }^{5}$ Department of Information Management, University of The Punjab, \\ Lahore, PAKISTAN \\ Department of Information Management, Nanjing University, \\ Nanjing, CHINA \\ e-mail at: jabeenmunazza@outlook.com (corresponding author); \\ ch.m.imran.sarwar@gmail.com; kamal.badar1980@gmail.com; dr.rafiqm@gmail.com; \\ misbah.jawwad@yahoo.com; liuyun@bit.edu.cn
}

\begin{abstract}
The present study is the first of its kind as it attempts to ascertain the current status of library and information science (LIS) research from the Chinese perspective, by focusing on English research contributions by Chinese LIS scholars. Leading contributors; individual (author) contributors; institutional contributors, and research collaborations were examined. The review comprises 564 articles published in international journals indexed by Social Science Citation Index (SSCI) from 2012-2013. Co-authorship analysis and co-citation analysis were used to draw the results. The results revealed two major findings; first, the Chinese research community is engaged in focusing on cross-national collaboration to establish their existence in international literature and establish colleague relationship with foreigner researchers. USA, UK, and Belgium are the primary counterparts of international collaborative papers. Chinese institutions have eminent professors in the LIS field who incorporate internationaloriented scholarly researches (48.04\%) around the globe. Secondly, Chinese researchers have enough knowledge to conduct research, both as single authors (26.24\%) and through internal academic collaboration between senior and junior researchers. The Chinese LIS research community has not paid much attention to conducting research on inter-institutional level (7.20\%) and on inter-regional level (6.73\%). Nevertheless, Wuhan University, City University Hong Kong, and Chinese Academy of Sciences have emerged as the leading institutions in producing LIS publications. Chinese immigrant scholars also have contributed to LIS China's international scientific collaboration. It is a worthwhile and unique study as it examines the collaboration trends networks analysis of international publications by Chinese scholars.
\end{abstract}


Keywords: LIS Research, Co-citation analysis, Co-author analysis, International Collaboration, Scietific Collaboration.

\section{INTRODUCTION}

With the advent of the first collaborative paper published in 1665 (Luukkonen 1992), scientific collaboration, as an effective methodology, globally attained a prominent position in various disciplines (Chang and Huang 2013, Franceschet 2010; Glänzel 2002; Harter and Kim 1997; Larivière, Gingras, and Archambault 2006).

With the rapid growth of information communication technology, the world has become a global village. In today's scenario, international co-authorship has facilitated convenient collaborative research in any field worldwide (Glänzel 2002; Larivière, Gingras, and Archambault 2006; Liu 2012).

Usually author, institution and country collaborations are the main methods to evaluate scientific collaboration. Co-authorship analysis is considered to be a key component in institution and country collaboration. As Katz (1997) described co-authorship could not be paralleled with collaboration. It is the an important technique to measure collaboration. Coauthorship analysis provides a substitution for count scientific collaboration, and it is a measurable assessment tool in identifying collaboration indicators and to reveal the level of collaboration among academicians (Åström and Hansson 2013; Katz 1997).

The emphasis of the Chinese Governement has been placed on excelling in the quantity and quality of research in science and technology at universities and research institutes. Special measures have been taken to initiate combined international collaborative projects among different countries. But as far as social sciences and management science is concerned, the Ministry of Education, China has not paid much attention to it (Rongping et al. 2008). The present study provides the analysis of Library and Information Science (LIS) literature and focuses on the collaborative network of Chinese scholars. This analysis also points out that LIS is in its infancy stage in China. It is the first research of its nature which examines the international publications trends of LIS by Chinese scholars based on the last two years (2012-2013). Hence, it is a worthwhile and unique study as it examines the collaboration trends networks analysis of international publications by Chinese scholars. The results of this study will provide not only a holistic understanding of the knowledge of librarianship in China but will also help to understand its theoretical foundation and the extent of research collaboration.

It will also not only provide deeper insight into the LIS field in China, but also would explain the theoretical underpinning and existence of research collaboration. Researchers from other disciplines or countries can use the same strategy to conduct similar studies in other disciplines.

\section{LITERATURE REVIEW}

Usually bibliometric analysis is used to measure research collaboration (such as number of publications, number of citations and bibliographic coupling) in order to provide a genral overview of a scientific research field. There are various sorts of bibliometric analysis to investigate collaboration activities (Chang and Huang 2012; Franceschet 2010; Gazni 2012; 
Larivière, Gingras, and Archambault 2006) on country distribution (Tang 2011), collaboration pattern analysis (Lee et al. 2012) and level of interdiciplinarity (Chang and Huang 2012).

The existing research indicates that collaborational activities and patterns vary from discipline to discipline (Franceschet 2011; Gazni 2012). Precisely, collaborative activites in social science and humanities are fewer in number as compared to those of natural science (Franceschet 2010; Larivière, Gingras, and Archambault 2006,). Furthermore, various studies have revealed a growing collaboration trend at national and international level in different areas (Ardanuy 2012; Dees 2015; Kliegl 2011; Lee et al. 2012; Ponti 2013; Wolfram 2012).

In a collaborative environment, the institution is the key component in scientific research. According to Yan (2011), an institution is a firm and representative component for the production, dissemination, and ingestion of knowledge. Huanwen (1996) and Xiao (2015) remarked that the main focus of Chinese LIS researchers was based on theory and historical method of research. Further, the findings highlighted the fact that many eminent scholars in LIS China have not been considered masters in methodologies of scientific research. Rochester and Vakkari (2004) reprted that there has been a remarkable expansion in LIS literature and education in China and currently efforts are underway to improve its quality. Smith (2009) discovered that 11 library and information schools offer doctoral degree programs motivating to examine the research outcomes of these research programs in this area. As Zhou, Su, and Leydesdorff (2010) pointed out, using citation patterns may seem tedious given the communication structure in Chinese for social sciences journals; consequently Chinese scholars cite fewer references to journal publication as compared to their international colleagues. It was also declared that subjects which fall under Chinese social sciences; especially Political Science, Marxism and Library and Information Science, are far less specialized in terms of disciplinary delimitations than their international counterparts. However, no attention has been paid by Chinese scholars to ascertaining the inner structure of scientific collaboration on institutional level and individual level. Neither has any study focused on analysis of collaboration patterns related to international publications of LIS.

Bibliometric analysis deals with a number of publications, citations, authors and other quantitative indicators. It does not support deeper understanding of the communication among different research groups. With the practice of network analysis tool-kit, social network analysis has now attained a prominent position in exploring the sequential growth in several fields (Franceschet 2011; Newman 2001). Different scientific networks introduced different information structures which can be applied in highlighting the phenomenon and underlining theories in scientific activities. Previous research presented a deeper insight into scientific collaboration from different dimensions and with new directions and suggestions of global scientific collaboration in LIS (Gazni 2012; Han et al. 2014; Katz 1997; Sin 2011; Yan 2011).

\section{OBJECTIVE, MATERIALS AND METHOD}

Bibliometric techniques have proved to be a reliable method for describing deeper understanding in a research field. In this research, it has been utilized to portary the current status of Chinese Library and Information Science research. To attain specific goals, two different methods were used. Firstly, it investigated how Chinese LIS research has been accomplished with collaborative network on co-authorship analysis have been established 
and secondly co-citation analysis has also been used to illustrate the real structure and foundational therories and concepts of LIS. However, the major purpose of this study is to explore collaboration patterns, trends, inner structures of leading research groups in collaboration set up by Chinese scholars on inter institution (II), inter regional (IR), cross regional (CR) and cross national (CN) at author and insitution levels.

The study is based on the following research questions:

RQ1. For Chinese research community, who are the main contributors in the LIS profession? RQ2. How do Chinese LIS researchers collaborate within country, or internationally, using collaborative networks?

$\mathrm{RQ3}$. What are the main theories and underlying principles of research as conducted by Chinese LIS scholars?

This study consists of 2012-2013 bibliographic data retrieved from SSCl database. The data source contains articles from all types of documents. WoS is considered a reliable source and large scale of data on author, journal, subject and country contribution based information (Herther 2009; Moed 2005). Basic search technique was used with query Year published (YP) 2012-2013 boolian opertor AND used to reterive data. All the records including 'China' were addressed. The schematic for retrieving data is shown in Figure. 1. A total of 581,711 documents from 2012 to 2013 were found in Social Science Citation Index (SSCl) indexed journals. The results were restricted to only type of articleby selecting the Web of Science (WoS) category of Information Science \& Library Science research by Chinese scholars consisting of 597 documents, on all types of documents only 564 LIS research articles were included for present study. We have obtained SSCI expanded database for present study, and relied on impact factor journals of publications. All the retrieved bibliographic data was checked manually to remove author name, co-author name ambiguities. We created a separate excel sheet to clarify author name, institutional, productivity and collaboration. Before starting analysis, several problems should be addressed. First of all, focus has been placed on those papers in which China appeared in reprint addressed field; therfore there is a possibility that some papers may have been overlooked. Secondly, Hong Kong and Macau are included, because they are a part of mainland China, which is considered to be one of the countries in the WoS data base. Thirdly, some records are not based on standards as author address field is incomplete and in some cases address field is also missing. Therefore, to make sense, the data needs to be standarized. We verified the non-standard data and added all the required pieces of information.

VosViewer software, designed to be used for examining bibliomteric networks, was used to interpret the data. It maps the publications, authors, journals based citation analysis, bibliographic coupling network and co-citation analysis. It provides a graphic representation of collaborative social network and intellectual organization of the LIS field. 


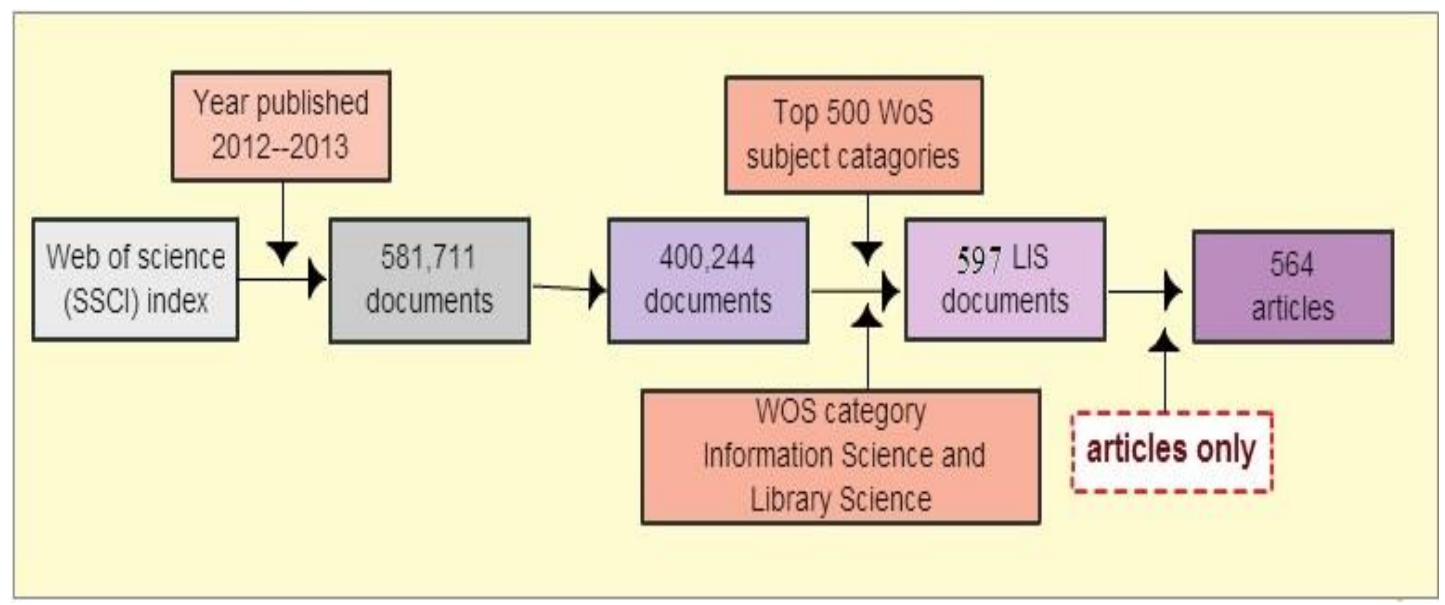

Figure 1: Schematic Illustration of Retrieving Data

\section{Theory Behind - Co-authorship Analysis in Collaborative Network}

Scientific research has become a collaborative endeavour as significant number of research papers are published using collaborative efforts (Subramanyam 1983). For this developing trend, it can be said that serious type of research production is based on networking among interactive scholars rather than individual authors. Co-authorship analysis is a formal expression which coonotes intellectual collaboration in any scientific research (Acedo et al. 2006). To investigate the extent to which LIS research prevailed in China, co-authorship analysis was adopted to find the social network trends netted from co-authored research articles. In co-authorship analysis, close and frequent collaboration means high similarities between scholars and groups who are closely working with or are linked to each other. Nodes represent the weight of the relationship between two scholars as to what they had collaboratively produced and the links show how strong the symbiotic relationship is (Acedo et al. 2006; Liu 2005). It is concluded that co-authorship analysis is a useful tool for approximation of collaboration rather than an objective representation of actual reality.

\section{Theory Behind - Co-citation Analysis}

Co-citation analysis is a systematic approach to understanding the theories and concepts related to previous LIS research in China. Citation analysis is a general term used in a couple of techniques for bibliomteric studies during scientific scholarly communication. It has been applied for decades in several studies as an assessment instrument for author, journal, organization, research performance of university departments and published works (Herther 1996). First of all, citation analysis is based on the hypothesis that if a scholar cites an article, it means that he or she considers it worthwhile.It clarifies the citation of an article which indicates its scholarly impact on citing work (Ratnatunga and Romano 1997). Secondly, the accumulated total number of citations in the same work designates its impact on research and scholarship (Herther 1996). The term "co-citation" is specifically used to classify clusters of recurringreferences (Small 1973). It is considered to be one of the main quantitative techniques to define dynamic aspects of scientific research by using structure mapping (Braam, Moed, and Van Raan 1991). Citation analysis also assumes that if a couple of articles are cited in the same document, it means that they are very similar to each other. Citation analysis is a source used to analyse the special feature of scientific research. In the present study, the focus has been placed on the fact that if two or more works are cited a specific number of times, then the topics, subject or underlying concepts are similar. 


\section{RESULTS}

\section{Leading Individual Contributors}

From 2012-2013, 1276 Chinese scholars contributed 564 articles. A Chinese author rank list was made on the basis of total contribution by Chinese-based authors. The top 20 authors along with the number of publications were identified (as presented in Table 1), elaborating the interests of LIS authors through various publication outlets. In this list, Rousseau, R, a professor in Katholieke University, Belgium has produced the highest number of publications. His interests include citation analysis, text mining, and information retrieval. Another interesting result is that Zhang, J, assistant professor in University Texas Arlington, USA has also published his research, under Chinese host institutions, at Fudan University of China.

Table 1: Top 20 Leading Contributors in LIS Literature in China (2012-2013)

\begin{tabular}{l|l|l||l}
\hline \hline Rank & $\begin{array}{c}\text { No. of } \\
\text { publications }\end{array}$ & \multicolumn{1}{|c}{ Author } & \multicolumn{1}{c}{ Institutes } \\
\hline \hline 1 & 18 & Rousseau, R & Zhejiang Univ / Katholieke Univ, Belgium \\
\hline \hline 2 & 11 & li, X & Univ Hong Kong \\
\hline \hline 3 & 10 & Ye, FY & Nanjing Univ \\
\hline \hline 4 & 10 & Zhang, XJ & Hong Kong Univ Sci \& Technol \\
\hline \hline 5 & 9 & Wang, XW & Dalian Univ Technol \\
\hline 6 & 8 & Zhang, J & Univ Texas Arlington, USA/ Fudan Univ, China \\
\hline 7 & 8 & Zhang, L & Hong Kong Polytech Univ \\
\hline \hline 8 & 8 & Liu, XP & Sun Yat Sen Univ \\
\hline \hline 10 & 8 & Huang, MH & Res Ctr Strateg Sci \& Technol China/ Natl Taiwan Univ \\
\hline 11 & 8 & Chen, J & Shanghai Univ Finance \& Econ/ Natl Univ Singapore \\
\hline 12 & 7 & Chen, CF & Wuhan Univ \\
\hline \hline 13 & 7 & Li, J & Wuhan Univ \\
\hline 14 & 7 & Liu, YX & Tongji Univ \\
\hline 15 & 8 & Wung, L & Sichuan Univ \\
\hline \hline 16 & 7 & He, DQ & Wuhan Univ \\
\hline \hline 17 & 7 & Li, J & Wuhan Univ / Univ Pittsburgh, USA \\
\hline \hline 18 & 7 & Wang, L & Wuhan Univ \\
\hline \hline 19 & 6 & Ma, FC & Wilin Univ \\
\hline 20 & 6 & Tang, J & Tsinghua Univ Univ \\
\hline \hline & & & \\
\hline \hline
\end{tabular}

\section{Leading Institutional Contributors}

During the period of study, 1276 authors belonged to 438 institutions, contributed articles to various journals. The top 10 LIS institutions are presented in Table 2 . Every university has different publishing strategies. As Table 2 indicates, Wuhan University, City University Hong Kong, Chinese Academy of Science and Zhejiang University have put significant efforts to publish papers in collaboration with indigenous and international scholars, while Fudan University, Dalian University Technology, Nanjing University, Tsinghua University and Peking University of China have also paid attention to maintaining their contribution in international publications. 
Table 2: Top 10 Leading Institutions in in LIS Literature in China (2012-2013)

\begin{tabular}{|c|c|c|c|c|}
\hline Rank & Institution name & $\begin{array}{c}\text { No. of } \\
\text { publications }\end{array}$ & Percentage & Region \\
\hline 1 & Wuhan University & 70 & 21.41 & Wuhan \\
\hline 2 & City University Hong Kong & 55 & 9.75 & Hong Kong \\
\hline 3 & Chinese Academy Sciences & 45 & 7.97 & Beijing \\
\hline 4 & Zhejiang University & 26 & 4.6 & Zhejiang \\
\hline 5 & $\begin{array}{l}\text { Hong Kong Poly Technology } \\
\text { University }\end{array}$ & 25 & 4.43 & Hong Kong \\
\hline 6 & Fudan University & 23 & 4.07 & Shanghai \\
\hline 7 & Dalian University technology & 23 & 4.07 & Liaoning \\
\hline 8 & Nanjing University & 22 & 3.9 & Jiangsu \\
\hline 9 & Tsinghua University & 22 & 3.9 & Beijing \\
\hline 10 & Peking University & 19 & 0.19 & Beijing \\
\hline
\end{tabular}

\section{Collaborative Network of Authors}

Co-author analysis provides not only a clear picture about the level of collaboration between authors and institutions, but also elaborates the idiosyncratic position that they occupy. The Co-authorship map provides a detailed explanation of the second research question of the present study namely: How do Chinese LIS researchers collaborate within the country or internationally by using collaborative networks. Keeping this purpose in mind, the whole data has been classified into five different types of collaboration:

i. Publication by single author (SA),

ii. Publications co-authored by authors within same institution (II),

iii. Publication co-authored by authors in different institutions but within same province or region (IR),

iv. Publications co-authored by authors in different provinces or regions of China (CR), and

v. Publications co-authored by authors in different countries, where researchers belong to different research institutes, departments and countries (CN), (Wang et al. 2005).

All articles are classified according to the above-mentioned perimeters. If an article has more than one collaborations, then it should be classified in accordance to the following priority rule:

\section{$\mathrm{SA}>\mathrm{II}>\mathrm{IR}>\mathrm{CR}>\mathrm{CN}$}

\section{Co-authorship Maps in LIS Research}

Figure 2 elaborates the level of collaboration in Chinese LIS research. In this scrappy map, several clusters are identified without strong links between them. Cluster 1, 3, and 5 are the largest clusters as compared to others and indicate that they have a strong commitment to undertake collaborative research on the national and international level. Researchers falling under cluster 3 have a strong association with foreigner researchers. Rousseau, $\mathrm{R}$ has a strong connection with Ye, FY (Nanjing university), Hu, XJ (Zhejiang university) and Liu, YX 
(Tongji university) of China. The level of collaboration between international scholars and Chinese scholars is not only based on assisting and monitoring research plans But also, it is established on the joint efforts of senior researchers (Floyd 1994). Similar results can be found fin the other clusters, all scholars included are from Chinese universities as well as western countries.

Another significant point is that central positions are occupied in Figure 2 by PhD supervisors and deans of LIS schools while the smaller circles are surrounded by individual contributors or by PhD candidates (Floyd 1994). From cluster 1, it can be seen that an inter-institutional research tendency can be seen in the work of Prof Chen, CF has received strong node and produced a total 7 of publications with Wang, $\mathrm{P}$ and Tian MY from school of Information Management, Wuhan university, China.

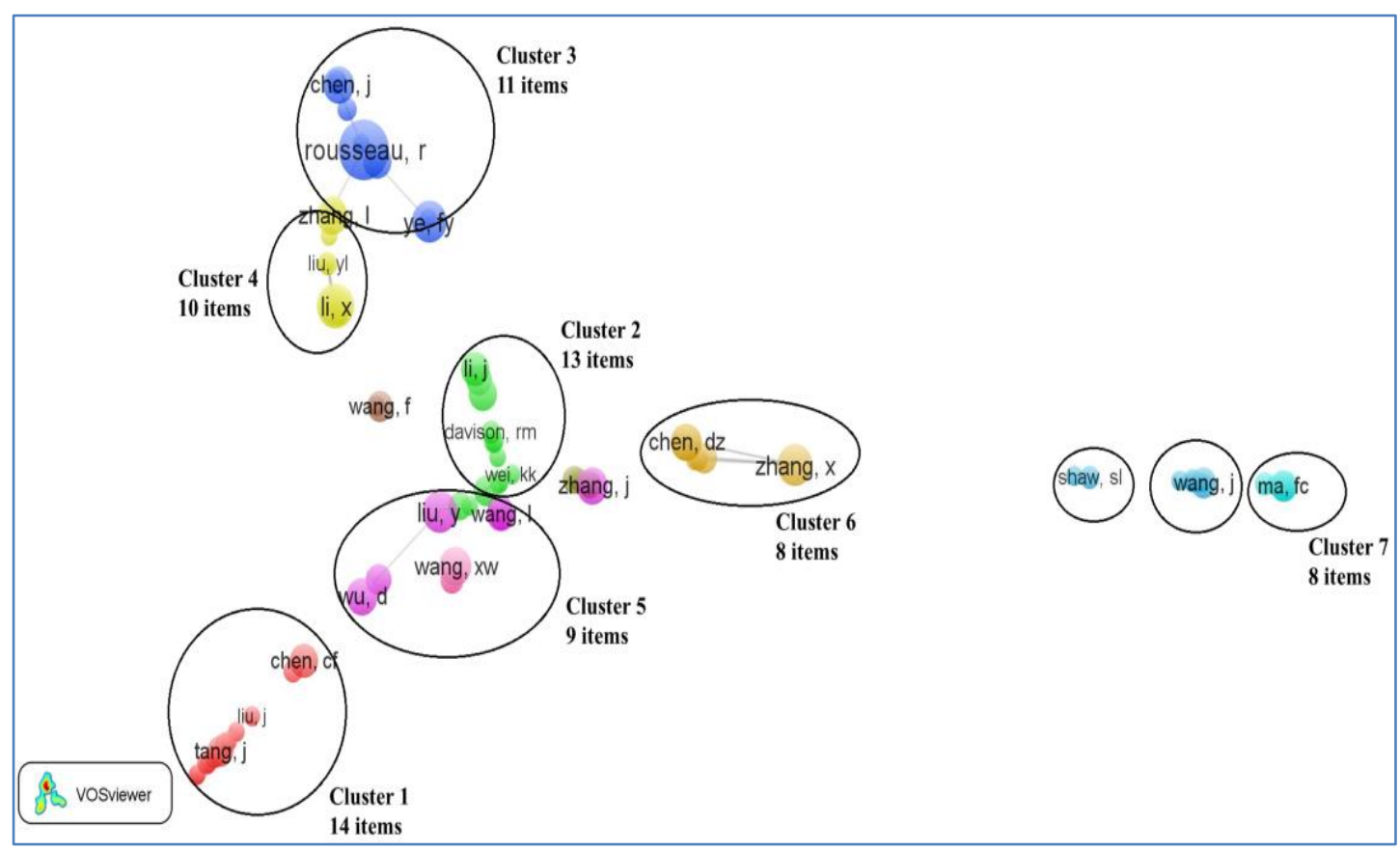

Figure 2: Co-authorship Map in International-oriented Research

Similarly, Figure 3 illustrates co-authorship map at institutional level, which shows that a sufficient number of universities are interlinked in research network. A significant point is that $48.04 \%$ articles have been produced by collaborative efforts. This illustrates the fact that scientific communication between researchers is wide and apparent. It also shows that intellectual communication among LIS scholars is more inclusive and externally oriented. The map contains six universities from the US (University of Pittsburg, Georgia state university, Indiana University, Georgia institute of technology, Drexel University and university of Nevada), two universities from UK (Brigham University and University of Sheffield) two universities from Germany (University of Antwerp and Khatolieke University Leuven), which signifies that various institutions frequently collaborate with Chinese researchers.

The levels of collaboration of Chinese institutions are described and measured in Table 3. Cross-national (CN) oriented research collaboration is the key element, accounting for 48.04 percent of the whole research articles. The proportion of cross- regional (CR) research has a share of 12.76 percent. Besides this single-authored research, it has attained the second position whereas more than $24 \%$ research was conducted by a single author, which indicates that research conducted by a single author is considered more authentic than interinstitutional (6.20) and inter-regional research (6.73\%). 


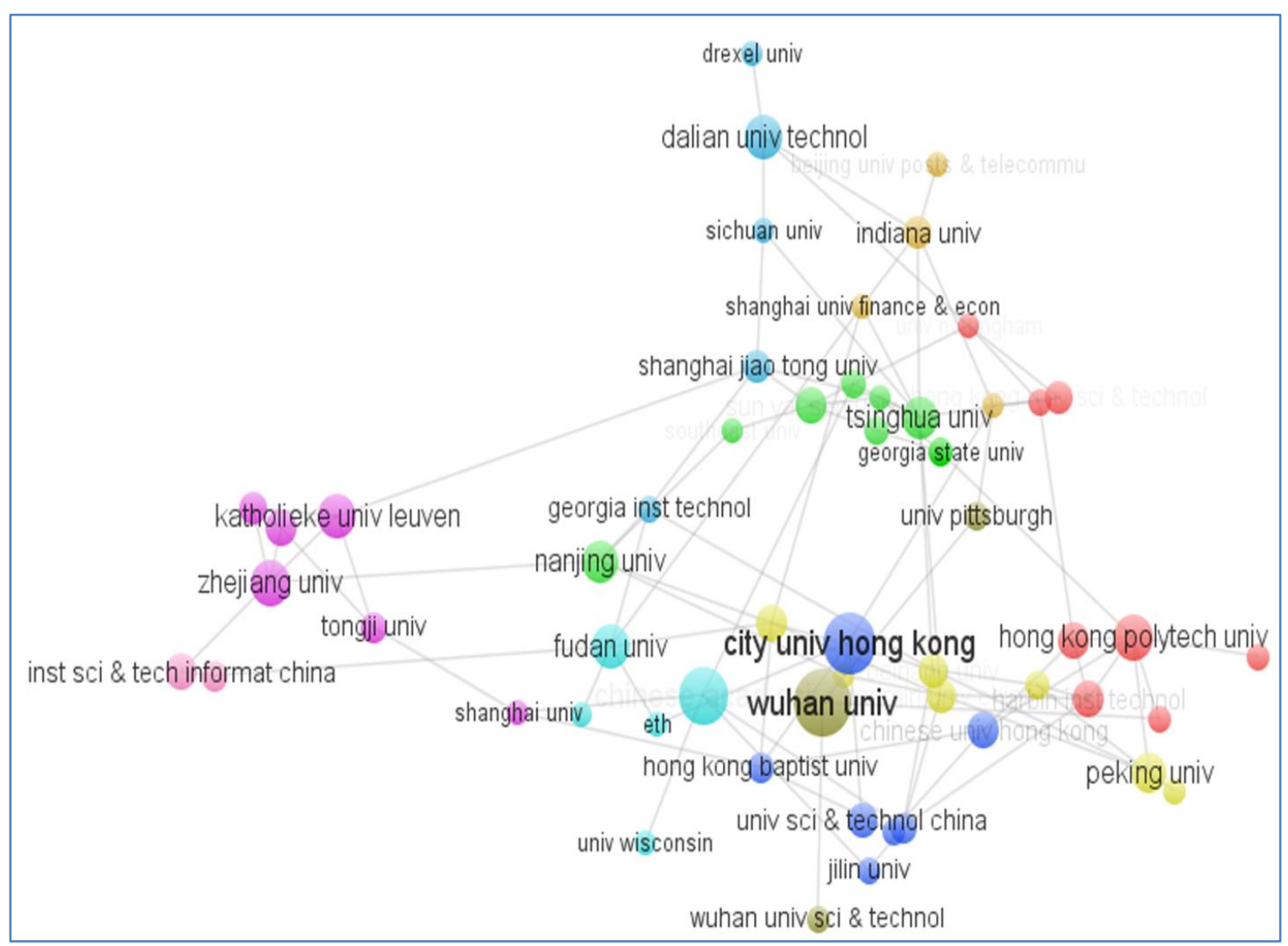

Figure 3: Co-authorship of LIS research (Institutional Level)

China has produced 293 (52\%) articles on an individual author basis during 2012-2013 and $271(48.04 \%)$ as collaborative publications. United States, Belgium, England, Singapore and Taiwan were the most collaborative countries. Almost half $(47 \%)$ of the total collaborative publications were led by United States, leaving the second and third contributors, Belgium and England (10\% and $8.11 \%$ respectively) far behind. China's collaboration reflected by international publications shows the high rate of collaboration among Chinese and international LIS institutions (Figure 4).

Table 3: Collaborative Types of LIS Research

\begin{tabular}{lccccc}
\hline $\begin{array}{c}\text { Collaborative } \\
\text { type of research }\end{array}$ & $\begin{array}{c}\text { Single } \\
\text { author }\end{array}$ & $\begin{array}{c}\text { Inter- } \\
\text { institutional }\end{array}$ & $\begin{array}{c}\text { Inter- } \\
\text { regional }\end{array}$ & $\begin{array}{c}\text { Cross- } \\
\text { regional }\end{array}$ & $\begin{array}{c}\text { Cross- } \\
\text { national }\end{array}$ \\
\hline No. of articles & 148 & 35 & 38 & 72 & 271 \\
Percentage & 26.24 & 6.20 & 6.73 & 12.76 & 48.04 \\
\hline
\end{tabular}




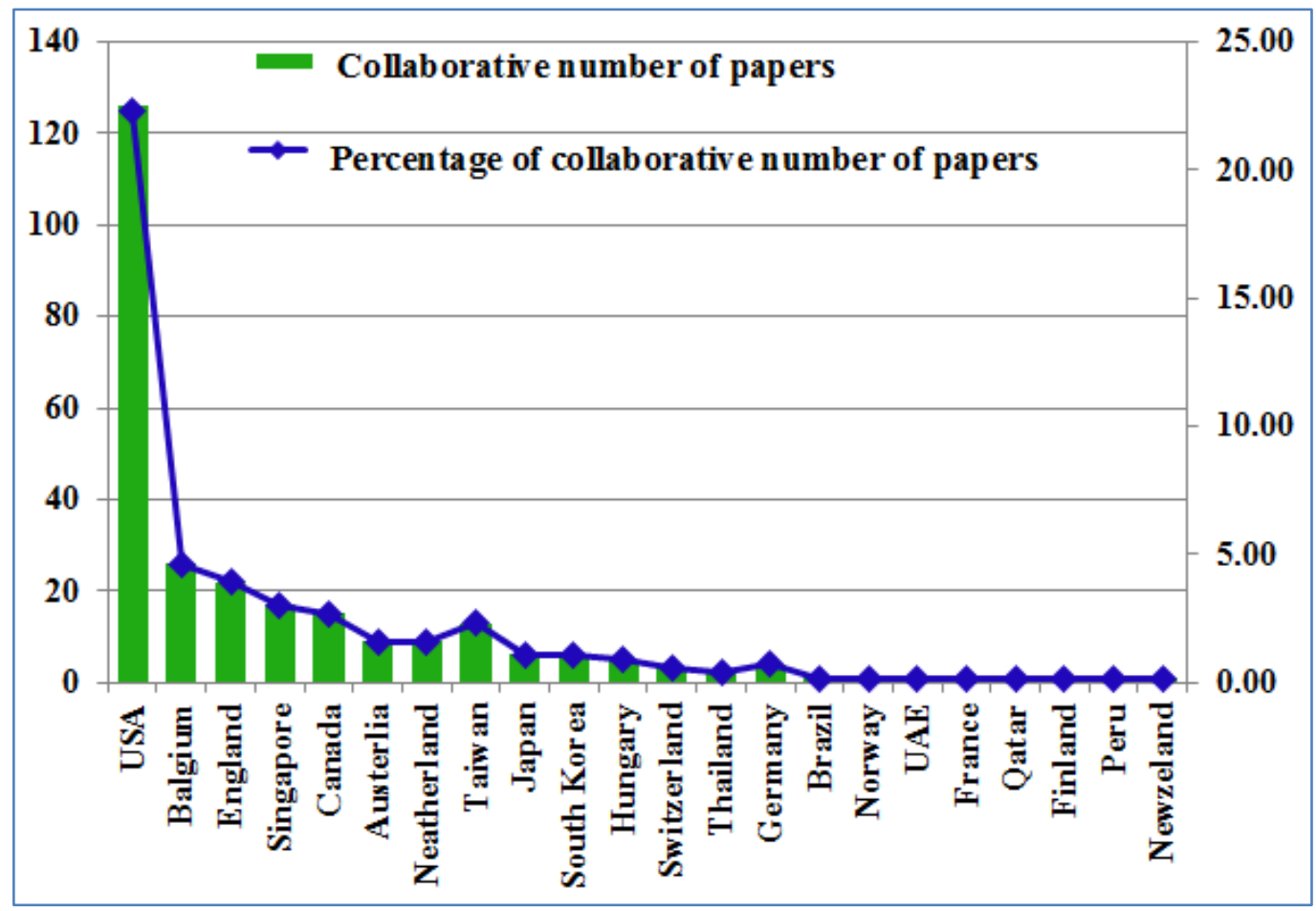

Figure 4: Collaborative LIS Publications with China (2012-2013)

\section{Underlying Theories and Concepts}

This analysis addressed a third pertinent question namely "What are the main theories and underlying concepts in research by Chinese LIS scholars?" The co-citation map facilitated a better understanding of "theory based concept clusters." Furthermore, to explain this research question, details of about 15 most cited works, which have significantly influenced LIS research in China, were delineated.

\section{Analysis of co-citation map}

During 2012-2013, entire samples of 20,588 references were cited. Categorically, a researcher has to set an appropriate threshold of the popularity of the cited references. At this stage, the purpose was to find proper parameter settings, and to illustrate a map based on many units so that sufficient granularity would be possible to visualize the scientific structure of the field. One bibliometric expert was consulted and a consensus was developed to set the appropriate parameters settings.

\section{Co-citation map of LIS research}

Co-citation map has six clusters that have a strong focus on management and information research (Figure.5). Cluster 1 with red nodes: These basically addresses social behavioral and user satisfaction related issues to find out theoretical integration of technological acceptance. The second perspective indicates dispersion of innovation, talks about how, why and at what level new technologies and ideas spread through clusters and re-conceptualize the role of information technology contemporarily (Sambamurthy, Bharadwaj and Grover 2003). Cluster 2 with green nodes: A close link of works contains citation analysis and bibliometric studies. The influential works by Aksnes (2003) and Bar-Ilan (2008) gained central attention in bibliometric based studies; indicating highly cited articles, quite different from ordinary cited articles. Furthermore, it attained a huge number of citation based on broader subject area from close and remote fields. Scientometrics studies, which are 
comprehensively employed in behavioral and management sciences, demonstrate the actual trends and growth. It is also considered to be the main focus area in LIS research (Almind and Ingwersen 1997). Cluster 3 with blue nodes: A relatively small cluster of works, consisting of concepts of ecosystem management, modelling, and analysis. In addition, a number of research articles based on sustainable development and evolution in agriculture were included. (Xu, Liang, and Gao 2008; Xu et al. 2009; Xu and Xu 2011). Cluster 4 with yellow nodes: A small cluster of works, concentrating on information communication technology (ICT) policy making, especially in the context of $3 \mathrm{G}$ mobile technologies, challenges and prospects in China. These articles portray a picture of ICTs information policy linkages with respect to rural development of China. Years 2012-2013 observed a boom in the 3G technology around the world (in contrast to China), which led the Chinese researchers to focus more on policy making related to telecommunication (Xia 2011; Zhang and Liang 2011). Cluster 5 with purple nodes: represents the examination of human behavior and communication activities and study about online social structure (Butler 2001, Forman, Ghose, and Wiesenfeld 2008). The cluster showed an advent of ecological disasters, supported by various activities like dam building and drawing rivers. Cluster 6 with light blue nodes: A relatively wide cluster, which had several linkages with cluster 1 and 5 as shown in Figure 5. Studies in this cluster concentrate on different research theoretical aspects such as qualitative research, social inequality, ground theory, techniques, and procedures.

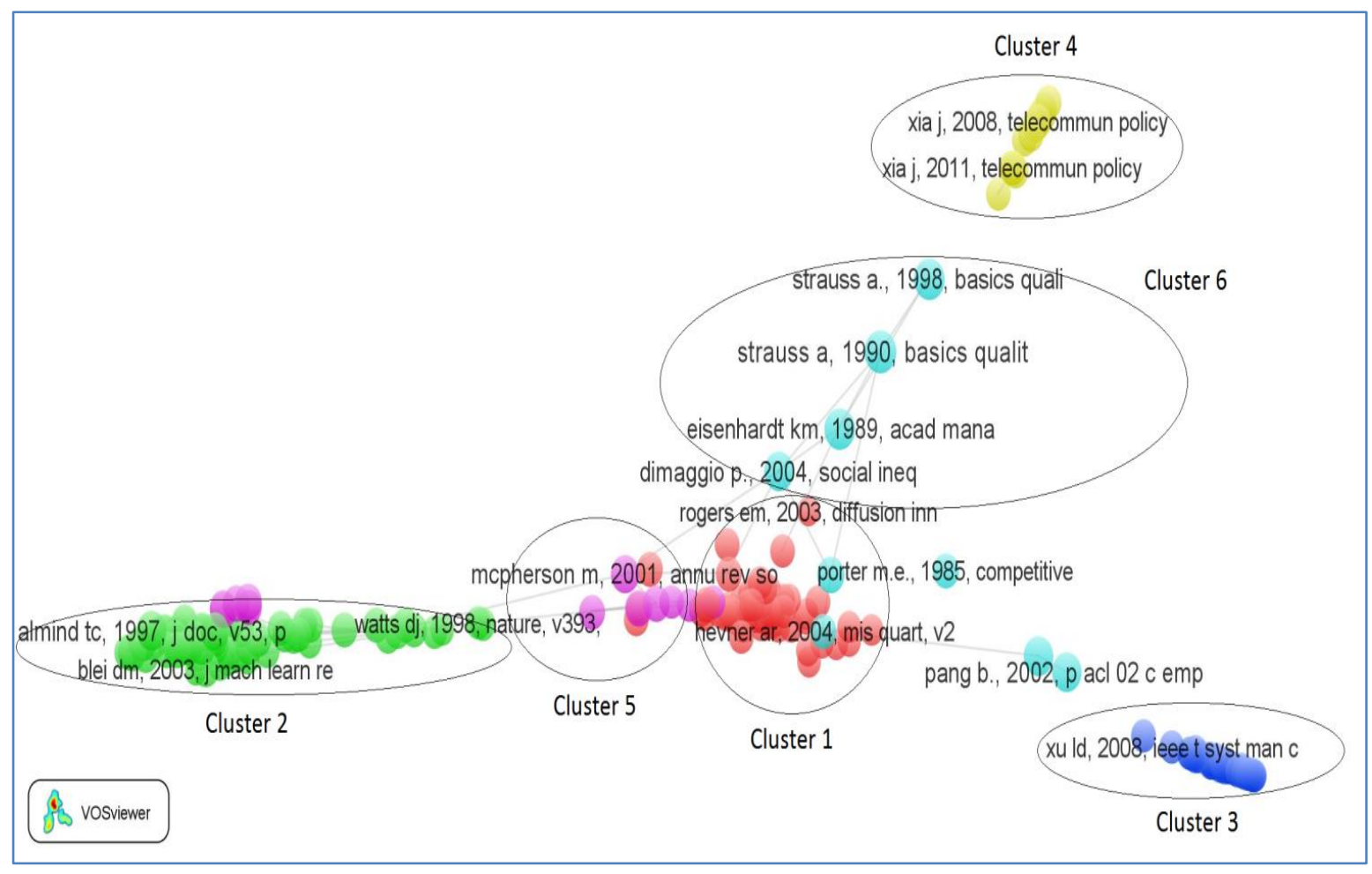

Figure 5: Co-citation Map

\section{Most cited works}

To address the third research question, Table 4 presents ranks of the top 15 research articles based on total citations. It expresses the LIS research cited by Chinese scholars based on different perceptive resources. Firstly, "theory and procedure on qualitative research" is a topic, which has been explored with an emphasis on qualitative research rigor. The influential works by Strauss A $(1990 ; 1998)$ provides the basis for qualitative research, 
grounded theory procedures and techniques. Secondly, five works out of 15 (33.33\%) were related to scientometrics analysis and approaches as appear in the present research, indicating a plummeting trend in studying scientometrics applications in LIS research. Thirdly, research depends considerably on work presented/conducted in United States, although contributions by Chinese scholars have received immense attention by LIS scholars. Seven top cited articles out of 15 (46.7\%) written by US scholars reflect the influence of US contributions on the present LIS study. Last but not the least, it should not be ignored that the contributions of two Chinese scholars, Chen YB and Chen CM, China born but currently serving in US leading universities, produced quality work and were frequently cited in LIS research.

Table 4: Top 15 Highly-Cited Works

\begin{tabular}{r||r||r||r||r}
\hline \hline Rank & \multicolumn{1}{c||}{ Total citations } & \multicolumn{1}{c||}{ Author } & Country & Year \\
\hline \hline 1 & 504 & Strauss A & USA & 1990 \\
\hline \hline 2 & 461 & Strauss A & USA & 1998 \\
\hline \hline 3 & 411 & Pang B & USA/China & 2002 \\
\hline \hline 4 & 382 & Dimaggio P & USA & 2004 \\
\hline \hline 5 & 375 & Turney PD & Canada & 2003 \\
\hline \hline 6 & 342 & Mcpherson M & UK & 2001 \\
\hline \hline 8 & 337 & Leydesdorff L & Netherland & 2006 \\
\hline \hline 9 & 337 & Kaplan AM & France & 2010 \\
\hline \hline 10 & 311 & Forman C & USA & 2008 \\
\hline \hline 11 & 297 & Katz JS & UK & 1997 \\
\hline \hline 12 & 294 & Blei DM & USA & 2003 \\
\hline \hline 13 & 282 & Leydesdorff L & Netherland & 2009 \\
\hline \hline 14 & 278 & Chen YB & USA/China & 2008 \\
\hline \hline 15 & 270 & Chen CM & USA/China & 2004 \\
\hline \hline
\end{tabular}

\section{DISCUSSION}

Rousseau, $\mathrm{R}$ has a strong connection with Chinese LIS professionals belonging to different universities like Tongji University and Zhejiang University. Scholars (Zhang, J) from Chinese Academy of Science, Sichuan University (Wang, YD) and Dalian University of Technology (Wang, XW) seemed to be engaged in national-oriented research with sufficient contributions contributed in inter-institutional and inter-regional based collaborations relate to conducting, monitoring and directing research projects. The major findings are about collaboration by Chinese scholars, which are revealed in two extents. It can, therefore, be concluded that Chinese researchers have enough knowledge to conduct commendable research as single authors and they have strong internal academic communication between senior researcher and junior researchers.

On the other hand, Chinese institutions have eminent professors in LIS field who incorporate international-oriented scholarly research around the globe. LIS scholars who intended to establish their existence in international literature remained involved in international collaboration and established colleague relationship. This tendency can be found in Wuhan University (Chen, CF, Xia, JF), City University Hong Kong (Liu, BQ), Zhejiang University ( Ye, FY) and Peking University (Wu, LS). The results may be summarized as: 
a) It can be concluded that the most productive institutes are located in Beijing and coastal areas such as Shanghai, Jiangsu and Zhejiang of China.

b) Results show that some leading universities in LIS of China have their own eminent scholars, who generally try to occupy a significant position in collaborative research. They contributed to Chinese LIS research by initiating major ideas of basic research and monitoring junior researchers.

c) Cross national-oriented research is more developed which demonstrates that foreign researchers have a deeper interest in conducting research with LIS domestic Chinese researchers. Likewise, the collaboration analysis between Chinese and international institutions echo the result derived from the collaborative map of coauthorship (international-oriented research on institutional level), showing a strong international alignment and academic communication between Chinese LIS scholars and foreigners researchers.

d) Library oriented common research interests are information seeking behavior, information communication technology (ICT), bibliometric approaches and qualitative research; whereas comparison of different variants in using the index and ecological system fall under non library oriented research by Chinese LIS scholars.

e) Chinese scholars have produced a huge number of publications by themselves, as single author (SA) inter-institutional (II) and inter-regional (IR) collaboration. They are highly influenced by and have borrowed basic ideas from foreigners' researches.

\section{CONCLUSION}

The study sheds light on theories and underlying concepts of LIS research by using co-citation maps and top ranked works. The major conclusion drawn is that the LIS research is mainly based on learning of theories, social behavioral, and bibliometric conceptualization that have portrayed mature thinking of Chinese LIS researches. It relies on deeper western speculative frameworks. LIS research is a combination of information science, management, and library science. It has encouraged a connection of librarianship with a specific theoretical and conceptual framework to explain how it emerged, interlinked, and contributed knowledge in the LIS literature. LIS research can be defined to some extent as an amalgam of knowledge management, information science, and librarianship. International literature included a number of preeminent scholars. These scholars are seen as the touchstone of quality research; therefore, scholars from Chinese institutions, as well as scholars from other countries, are in involved with research communication with those preeminent scholars.

Researchers have deepened their understanding of Chinese librarianship by connecting the librarianship phenomenon from a Chinese perspective to the theoretical framework. LIS research in China is demarcated by a clear division; it is rising not only in terms of scholars in each community and collaborating network but also with respect to the theoretical foundation. LIS research is not in its infancy stage but a majority of Chinese LIS researchers has been engaged in research with foreign eminent scholars and professors on equal bases of knowledge sharing. The present study is delimited to the international publications trends of LIS by Chinese scholars based on the last two years (2012-2013) only. 


\section{ACKNOWLEDGMENT}

This research was undertaken at Beijing Institute of Technology Beijing, China. "The current status and scientific collaboration analysis of LIS research: China's perspective". We are thankful for BIT, the projects of National Science Foundation of China (NSFC, grant No. 71033001; 71273030) and the project of International Science and Technology Cooperation Program of MOST of China (grant No. 2012DFG11750) who supported this research

\section{REFERENCES}

Acedo, F.J., Barroso, C., Casanueva, C., and Galán, J.L. 2006. Co-Authorship in Management and Organizational Studies: An Empirical and Network Analysis. Journal of Management Studies, Vol.43, no.5: 957-983.

Aksnes, D.W. 2003. Characteristics of highly cited papers. Research Evaluation, Vol.12, no.3 : 159-170. doi: 10.3152/147154403781776645.

Almind, T.C. and Ingwersen, P. 1997. Informetric analyses on the world wide web: methodological approaches to 'webometrics. Journal of Documentation, Vol.53, no.4: 404-426. doi: 10.1108/EUM0000000007205.

Ardanuy, J. 2012. Scientific collaboration in Library and Information Science viewed through the Web of Knowledge: the Spanish case. Scientometrics, Vol.90, no.3 : 877-890. doi: 10.1007/s11192-011-0552-1.

Åström, F. and Hansson, J. 2013. How implementation of bibliometric practice affects the role of academic libraries. Journal of Librarianship and information Science, Vol. 45, no.4 :316-322.

Bar-llan, J. 2008. Informetrics at the beginning of the 21st century-A review. Journal of Informetrics, Vol.2, no.1 :1-52. doi: http://dx.doi.org/10.1016/j.joi.2007.11.001.

Braam, R.R., Moed, H.F., and Van Raan, A.F. 1991. Mapping of science by combined cocitation and word analysis I. Structural aspects. Journal of the American Society for Information Science, Vol.42, no.4: 233-251.

Butler, B.S. 2001. Membership Size, Communication Activity, and Sustainability: A ResourceBased Model of Online Social Structures. Information Systems Research, Vol.12, no.4: 346-362. doi: doi:10.1287/isre.12.4.346.9703.

Chang, H.W. and Huang, M.H. 2013. Prominent institutions in international collaboration network in astronomy and astrophysics. Scientometrics, Vol.97, no. 2: 443-460. doi: 10.1007/s11192-013-0976-x.

Chang, Y.W. and Huang, M.H.A. 2012. A study of the evolution of interdisciplinarity in library and information science: Using three bibliometric methods. Journal of the American Society for Information Science and Technology, Vol.63, no.1: 22-33. doi: 10.1002/asi.21649.

Dees, A.S. 2015. A Bibliometric Analysis of the Scholarly Publications of Librarians at the University of Mississippi, 2008-2013. The Journal of Academic Librarianship, Vol.41, no.3: 241-245.

Floyd, S.W., Schroeder, D.M. and Finn, D.M. 1994. Only if I'm first author : Conflict over credit in management scholarship. Academy of Management Journal, Vol.37, no.3 :734-747.

Forman, C., Ghose, A., and Wiesenfeld, B. 2008. Examining the Relationship Between Reviews and Sales: The Role of Reviewer Identity Disclosure in Electronic Markets. Information Systems Research, Vol.19, no.3: 291-313. doi: 10.1287/isre.1080.0193. 
Franceschet, M. 2011. Collaboration in computer science: A network science approach. Journal of the American Society for Information Science and Technology, Vol.62, no.10: 1992-2012. doi: 10.1002/asi.21614.

Franceschet, M., and Costantini, A. 2010. The effect of scholar collaboration on impact and quality of academic papers. Journal of Informetrics, Vol.4, no.4: 540-553. doi: http://dx.doi.org/10.1016/j.joi.2010.06.003.

Gazni, A., Sugimoto, C.R., and Didegah, F. 2012. Mapping world scientific collaboration: Authors, institutions, and countries. Journal of the American Society for Information Science and Technology, Vol.63, no.2: 323-335. doi: 10.1002/asi.21688.

Glänzel, W. 2002. Coauthorship patterns and trends in the sciences (1980-1998): A bibliometric study with implications for database indexing and search strategies. library trends, Vol.50, no.3: 461-473.

Han, P., Shi, J., Li, X., Wang, D., Shen, S. and Su, X. 2014. International collaboration in LIS: global trends and networks at the country and institution level. Scientometrics, Vol. 98 , no. 1 :53-72. doi: 10.1007/s11192-013-1146-x.

Harter, S.P. and Kim, H.J. 1997. ARCHIVE: electronic journals and scholarly communication: a citation and reference study. Journal of Electronic Publishing, Vol.3, no.2.

Herther, N.K. 2009. Research evaluation and citation analysis: key issues and implications. Electronic Library, Vol.27, no.3 :361-375. doi: 10.1108/02640470910966835

Huanwen, C. 1996. A bibliometric study of library and information research. Asian Libraries Vol 5, no. 2: 30 .

Katz, J.S. and Martin, B.R. 1997. What is research collaboration? Research Policy, Vol.26, no.1: 1-18. doi: http://dx.doi.org/10.1016/S0048-7333(96)00917-1.

Kliegl, R. and Bates, D. 2011. International collaboration in psychology is on the rise. Scientometrics, Vol.87, no.1: 149-158. doi: 10.1007/s11192-010-0299-0.

Larivière, V., Gingras, Y. and Archambault, E. 2006. Comparative analysis of networks of collaboration of Canadian researchers in the natural sciences, social sciences and the humanities. Scientometrics, Vol.68, no.3: 519-533.

Lee, D. H., Seo, I. W., Choe, H. C. and Kim, H. D. 2012. Collaboration network patterns and research performance: the case of Korean public research institutions. Scientometrics, Vol.91, no. 3: 925-942. doi: 10.1007/s11192-011-0602-8.

Liu, H.I., Chang, B.C. and Chen, K.C. 2012. Collaboration patterns of Taiwanese scientific publications in various research areas. Scientometrics, Vol.92, no.1: 145-155. doi: 10.1007/s11192-012-0719-4.

Liu, X., Bollen, J., Nelson, M.L. and Van de Sompel, H. 2005. Co-authorship networks in the digital library research community. Information processing \& management, Vol.41, no.6: $1462-1480$.

Luukkonen, T., Persson, O. and Sivertsen, G. 1992. Understanding Patterns of International Scientific Collaboration. Science, Technology, \& Human Values, Vol.17, no.1: 101-126. doi: $10.2307 / 689852$.

Moed, H.F. 2005. Citation Analysis in Research Evaluation (= Information Science and Knowledge Management, Bd. 9). Dordrecht.

Newman, M.E. 2001. Clustering and preferential attachment in growing networks. Physical Review E, Vol.64, no.2.

Ponti, M. 2013. Peer production for collaboration between academics and practitioners. Journal of Librarianship and Information Science, Vol.45, no.1 :23-37.

Ratnatunga, J. and Romano, C. 1997. A "citation classics" analysis of articles in contemporary small enterprise research. Journal of Business Venturing, Vol.12, no. 3: 197-212. 
Rochester, M. and Vakkari, P. 2004. International library and information science research: a comparison of national trends, IFLA professional reports, No. 82. The Hague: International Federation of Library Associations and Institutions.

Rongping, M., Zhongbao, R., Sida, Y. and Yan, Q. 2008. Technology foresight towards 2020 in China': the practice and its impacts. Technology Analysis \& Strategic Management, Vol. 20, no. 3: 287-307.

Sambamurthy, V., Bharadwaj, A. and Grover, V. 2003. Shaping agility through digital options: Reconceptualizing the role of information technology in contemporary firms. MIS Quarterly, Vol.27, no.2: 237-263.

Sin, S.C.J. 2011. International coauthorship and citation impact: A bibliometric study of six LIS journals, 1980-2008. Journal of the American Society for Information Science and Technology, Vol.62, no.9 :1770-1783. doi: 10.1002/asi.21572.

Small, H. 1973. Co-citation in the scientific literature: A new measure of the relationship between two documents. Journal of the American Society for information Science, Vol.24, no.4: 265-269.

Smith, K. 2009. Towards a research agenda for LIS in the East and Southeast (SE) Asian Region: Some preliminary thoughts. Asia-Pacific Conference on Library \& Information Education and Practice (A-LIEP 2009). Preparing Information Professionals for International Collaboration, 6-8 March 2009, University of Tsukuba, Japan.

Subramanyam, K. 1983. Bibliometric studies of research collaboration: A review. Journal of Information Science, Vol.6: 33-38. doi: 10.1177/016555158300600105.

Tang, L. and Shapira, P. 2011. Regional development and interregional collaboration in the growth of nanotechnology research in China. Scientometrics, Vol.86, no.2: 299-315. doi: 10.1007/s11192-010-0274-9.

Wixom, B.H. and Todd, P.A. 2005. A Theoretical Integration of User Satisfaction and Technology Acceptance. Information Systems Research, Vol.16, no.1: 85-102. doi: 10.1287/isre.1050.0042.

Wang, Y., Wu, Y., Pan, Y., Ma, Z. and Rousseau, R. 2005. Scientific collaboration in China as reflected in co-authorship. Scientometrics, Vol.62, no.2: 183-198. doi: 10.1007/s11192005-0013-9.

Wolfram, D. 2012. An Analysis of Canadian Contributions to the Information Science Research Literature: 1989-2008. Canadian Journal of Information and Library Science, Vol.36, no. 1-2: 52-66. doi: 10.1353/ils.2012.0005.

Xia, J. 2011. The third-generation-mobile (3G) policy and deployment in China: Current status, challenges, and prospects. Telecommunications Policy, Vol.35, no.1: 51-63. doi: 10.1016/j.telpol.2010.12.008.

Xiao, X., Zhang, F. and Li, J. 2015. Library and Information Science Research in China-A Survey Based Analysis of 10 LIS Educational Institutes. The Journal of Academic Librarianship, Vol. 41, no.3: 330-340.

$\mathrm{Xu}$, L., Liang, N., and Gao, Q. 2008. An integrated approach for agricultural ecosystem management. leee Transactions on Systems Man and Cybernetics Part C-Applications and Reviews, Vol.38, no. 4:590-599. doi: 10.1109/tsmcc.2007.913894.

$\mathrm{Xu}, \mathrm{L}$., Liu, H., Wang, S. and Wang, K. 2009. Modelling and Analysis Techniques for Crossorganizational Workflow Systems. Systems Research and Behavioral Science, Vol.26, no. 3: 367-389. doi: 10.1002/sres.978.

$\mathrm{Xu}, \mathrm{S}$. and Da Xu, L. 2011. Management: a scientific discipline for humanity. Information Technology \& Management, Vol.12, no.2: 51-54. doi: 10.1007/s10799-011-0090-9.

Yan, E. and Sugimoto, C. R. 2011. Institutional interactions: Exploring social, cognitive, and geographic relationships between institutions as demonstrated through citation networks. Journal of the American Society for Information Science and Technology, Vol.62, no.8: 1498-1514. doi: 10.1002/asi.21556. 
Zhang, J. and Liang, X.J. 2011. Business ecosystem strategies of mobile network operators in the 3G era: The case of China Mobile. Telecommunications Policy, Vol.35, no.2: 156171. doi: 10.1016/j.telpol.2010.12.009.

Zhou, P., Su, X. and Leydesdorff, L. 2010. A comparative study on communication structures of Chinese journals in the social sciences. Journal of the American Society for Information Science and Technology, Vol.61, no.7: 1360-1376. doi: 10.1002/asi.21343. 